\title{
Impact of exposure to ambient air pollutants on the admission rate of hospitals for asthma disease in Shiraz, southern Iran
}

\author{
Ziaeddin Bonyadi a , Hossein Arfaeinia b, c, Moradali Fouladvand ${ }^{\mathrm{d}}$, Sima Farjadfard ${ }^{\mathrm{e}}$, \\ Mohsen Omidvar ${ }^{\mathrm{f}}$, Bahman Ramavandi ${ }^{\mathrm{b}, \mathrm{c}, *}$ \\ ${ }^{a}$ Department of Environmental Health Engineering, Social Determinants of Health Research Center, Mashhad University of Medical Sciences, Mashhad, Iran \\ ${ }^{\mathrm{b}}$ Department of Environmental Health Engineering, Faculty of Health and Nutrition, Bushehr University of Medical Sciences, Bushehr, Iran \\ c Systems Environmental Health and Energy Research Center, The Persian Gulf Biomedical Sciences Research Institute, Bushehr University of Medical \\ Sciences, Bushehr, Iran \\ ${ }^{\mathrm{d}}$ The Persian Gulf Marine Biotechnology Research Center, Bushehr University of Medical Sciences, Bushehr, Iran \\ e Department of Environmental Engineering, Graduate School of the Environment and Energy, Science and Research Branch, Islamic Azad University, Tehran, \\ Iran \\ ${ }^{\mathrm{f}}$ Department of Occupational Health Engineering, Faculty of Health and Nutrition, Bushehr University of Medical Sciences, Bushehr, Iran
}

\section{H I G H L I G H T S}

- Asthma hospital admissions due to $\mathrm{NO}_{2}, \mathrm{SO}_{2}$, and $\mathrm{O}_{3}$ were estimated for Shiraz, Iran.

- AirQ ${ }_{2.2 .3}$ software was used for developing predictive models.

- Attributed equivalent modeled for hospital admission due to asthma disease (HAAD).

- The number of extra cases of HAAD for $<15$ years was estimated to be 273 for 2016.

- The yearly average concentration of $\mathrm{SO}_{2}$ was 8.62 times more than the WHO guideline.

\section{A R T I C L E I N F O}

\section{Article history:}

Received 26 June 2020

Received in revised form

18 August 2020

Accepted 19 August 2020

Available online 23 August 2020

Handling Editor: A. Gies

\section{Keywords:}

Air pollutants

AirQ model

Health effects

Asthmatic disease

Shiraz

\begin{abstract}
A B S T R A C T
Asthma is a common chronic respiratory disease in the world. Short-term exposure to ambient air pollutants is closely related to acute respiratory diseases and asthmatic symptoms. The purpose of this research was to estimate the correlation between exposure to three air pollutants $\left(\mathrm{O}_{3}, \mathrm{NO}_{2}\right.$, and $\left.\mathrm{SO}_{2}\right)$ and hospital admission because of asthmatic disease (HAAD) in the city of Shiraz, southern Iran. The data were collected from the two real-time monitoring stations located in this city. The acquired information was used for developing predictive models by the AirQ software. The findings of this study were reported for two age groups ( $<15$ and 15-64 years old). The highest levels of $\mathrm{O}_{3}, \mathrm{NO}_{2}$, and $\mathrm{SO}_{2}$ were obtained $187.33 \mu \mathrm{g} / \mathrm{m}^{3}, 34.1 \mu \mathrm{g} / \mathrm{m}^{3}$, and $491.2 \mu \mathrm{g} / \mathrm{m}^{3}$ in 2016 , respectively, and $227.75 \mu \mathrm{g} / \mathrm{m}^{3}, 92.26 \mu \mathrm{g} / \mathrm{m}^{3}$, and $190.21 \mu \mathrm{g} / \mathrm{m}^{3}$, respectively, in 2017. Among the mentioned pollutants, the yearly average concentration of $\mathrm{SO}_{2}$ was 8.62 times more than the WHO guideline, during the studied times. The number of extra cases of HAAD for $<15$ years and $15-64$ years caused by the air pollutants in Shiraz were estimated to be 273 and 36, respectively, in 2016, and 243 and 30 for 2017, respectively. The results of this work displayed that air pollutants have caused respiratory problems in Shiraz city. The AirQ model is a facile and potential tool for the prediction of asthma disease to reduce the health risk of atmospheric pollutants in the worldwide.
\end{abstract}

(C) 2020 Elsevier Ltd. All rights reserved.

\footnotetext{
* Corresponding author. Department of Environmental Health Engineering, Faculty of Health and Nutrition, Bushehr University of Medical Sciences, Bushehr, Iran. E-mail addresses: ramavandi_b@yahoo.com, b.ramavandi@bpums.ac.ir (B. Ramavandi).
}

\section{Introduction}

Asthma is one of the most common respiratory diseases, affecting 5 to 18 percent of people worldwide, especially children. People suffering from this disease have symptoms such as breathlessness and wheezing, which differ in frequency and severity from person to person (To et al., 2013). In involved people, asthma 
symptoms usually occur several times a day or week. For some people, these symptoms get worse during physical activity or at night. During an asthma attack, the lining of the bronchial tubes inflates, and therefore, with narrowing airways, the flow of air into and out of the lungs decreases. Asthma is often accompanied by symptoms such as sleeplessness, daytime fatigue, reduced activity levels, and school and work absenteeism. This type of disease has a relatively low mortality rate compared to other chronic diseases (Ghaffari et al., 2017).

Trasande and Thurston (2005) reported that acute respiratory syndromes embodied particularly in children with asthma were related to the ambient air pollutants such as particulate matters $\left(\mathrm{PM}_{2.5,10}\right)$, ozone $\left(\mathrm{O}_{3}\right)$, and nitrogen dioxide $\left(\mathrm{NO}_{2}\right)$. Moreover, last studies express a continuously increasing trend in outpatient visits and hospitalizations due to asthma incidence, likely resulting from exposure to the ambient air pollutants (Riedl and Diaz-Sanchez, 2005). The sources of air pollutants may create asthma, for example, the combustion of fossil fuels can cause airway inflammation via the mechanisms of oxidative stress (Poole et al., 2019). The organic and nonorganic pollutants at high concentrations, especially those placed on ultrafine particles $(<0.1 \mu \mathrm{m})$, cause to intensify asthma symptoms and to reduce lung function (Ghaffari et al., 2017). Asthma is more likely to occur in the homes and schools located in high-traffic areas than in low-traffic areas (Hauptman et al., 2020). However, in Iran like the rest of the world, mobile and stationary sources, including motor vehicles, industries, home heating, emit a wide variety of outdoor airborne pollutants (Seifi et al., 2019). Concerning the incidence of air pollution events following extreme dust storms, it can be declared that natural phenomena have an important role in the creation of asthma (Khaniabadi et al., 2017). In a study reported that exposure to aeroallergens such as pollen major trigger of asthma exacerbations (Murray et al., 2006). Nitrogen dioxide $\left(\mathrm{NO}_{2}\right)$ and sulfur dioxide $\left(\mathrm{SO}_{2}\right)$ are classified as primary criteria air pollutants while ozone $\left(\mathrm{O}_{3}\right)$ is classified as the secondary one. Nitrogen dioxide $\left(\mathrm{NO}_{2}\right)$ is one of a group of highly reactive gases that produce thought oxidation processes in which emitted nitrogen oxide reacts with atmospheric oxidizers such as $\mathrm{O}_{3}$. Road vehicles, heaters, and industrial activities with the burning of organic fuels can emit highlevel $\mathrm{NO}_{2}$ in the atmosphere. Sulfur dioxide $\left(\mathrm{SO}_{2}\right)$, regarded as a highly reactive corrosive gas in atmospheric pollutants, is mainly released from fossil fuel combustion in mining and industrial facilities. Both $\mathrm{NO}_{2}$ and $\mathrm{SO}_{2}$ pollutants are related to adverse impacts on the respiratory health (Ghaffari et al., 2017).

The AirQ software, designed by the WHO European Center for Environment and Health, is a valid and reliable instrument to assess the potential health impacts of air pollution and enable evaluation of scenarios specified by varied pollutants (Conti et al., 2017). This software collects, manages, and displays data obtained from criteria air pollutants (Conti et al., 2017). The mortality and morbidity due to exposure to outdoor air pollution in Mashhad metropolis have been estimated using the AirQ software (Miri et al., 2016). Asl et al. (2018) have quantified the health impacts of ambient air pollutants using the AirQ model approach in Hamadan city. Similar researches have used this software to estimate the health effect of air pollutants in other cities (Mokhtari et al., 2015; Nikoonahad et al., 2017). Based on Pierangeli et al. (2020) study, the number of asthma cases attributable to $\mathrm{NO}_{2}$ and $\mathrm{PM}_{2.5}$ (percentage of total cases) in Barcelona estimated to be 454 (18\%) and 478 (19\%), respectively. The relationship between short-term exposure to air pollutants $\left(\mathrm{PM}_{2.5}\right.$, $\mathrm{NO}_{2}, \mathrm{SO}_{2}$, and $\mathrm{O}_{3}$ ) and the increase of asthma exacerbations among children has been revealed (Liu et al., 2020).
This investigation was aimed to estimate asthma disease as a cause of admission to hospitals due to exposure to $\mathrm{O}_{3}, \mathrm{NO}_{2}$, and $\mathrm{SO}_{2}$ contaminants in Shiraz, Iran. Shiraz is the biggest city located in southern Iran with a semi-arid climate, so the acquired findings of this work can have broad applications for other cities in the world with a similar climate.

\section{Methodology}

\subsection{The study area}

Shiraz with a citizen count of $\sim 1.86$ million ( $49.57 \%$ woman and $50.43 \%$ man) is the central city of Fars Province and situated in southern Iran (Bonyadi et al., 2020). This city with a warm and semi-arid climate, an average annual temperature of $18.6{ }^{\circ} \mathrm{C}$, average wind speed of $10.78 \mathrm{~km} / \mathrm{h}$, average annual humidity of $39.5 \%$, and an average annual rainfall of $274.8 \mathrm{~mm}$ is located in geographical coordination of $29^{\circ} 36^{\prime} \mathrm{N}$ and $52^{\circ} 32^{\prime} \mathrm{E}$ and the elevation of $1540 \mathrm{~m}$ (Gharehchahi et al., 2013).

\subsection{The software of $\operatorname{AirQ}_{2.2 .3}$}

In this research, the AirQ model in different scenarios was used for measuring health outcomes resulting from short-term exposure to specific air pollutants including $\mathrm{O}_{3}, \mathrm{NO}_{2}$, and $\mathrm{SO}_{2}$. AirQ 2.2 .3 is a valid and reliable software for assessing the potential health effects of oxidant air pollutants, which combines the information of exposure-response and, then, estimates the health effects in a given population.

A causal association was presumed between the risk factor and the health impact to promote the validity of calculates in this program. In a specific time and city, the assessment of the health consequences of exposure to certain air contaminants was performed using the international software of $\mathrm{AirQ}_{2.2 .3}$.

The hygienic and epidemiological assessment was performed based on the attributable equivalent (AE), defined as the portion of the health outcomes in the desired population attributable by exposure to given atmospheric air pollutants, presuming a confirmed vital relationship between exposure and health consequence and no influenced by a notable interferes in that association (Bonyadi et al., 2020). The attributable equivalent (AE), which has a link to the exposure of an exact people during a fixed time, is calculated by the following formula:

$\mathrm{AE}=\Sigma([\operatorname{RHR}(\mathrm{c})-1] \times \mathrm{P}(\mathrm{c})) / \Sigma(\mathrm{RHR}(\mathrm{c}) \times \mathrm{P}(\mathrm{c}))$

Where $R H R(c)$ denotes the relative health risk due to an investigated pollutant in the aimed group, and $\mathrm{P}(\mathrm{c})$ denoted the equivalent exposed case in category " $c$ ".

The RHR parameter revealing the amount of a specified contaminant's effect on the health by an alteration in exposure to the polluted air is acquired via studied periods that assess the concentration alterations of air contaminants and their impacts on long-term health series (Rovira et al., 2020). This work was done based on the default WHO data available through AirQ software. The RHR values for $\mathrm{O}_{3}, \mathrm{NO}_{2}$, and $\mathrm{SO}_{2}$ were obtained from similar works (Ghaffari et al., 2017).

After specification the main frequency of health effects in the studied population, then the attributable exposure rate (AER) of the health effect can measure as: 
$\mathrm{AER}=\mathrm{I} \times \mathrm{AE}$

where the 'I' factor shows the baseline frequency of the health effect in the studied population. In this study, the proposed baseline frequency by WHO were used.

Finally, by Eq. (3) and knowing the size of the Shiraz population $(\mathrm{N})$, the number of cases attributed to the exposure (NE) is estimated as follows:

$\mathrm{NE}=\mathrm{AER} \times \mathrm{N}$

As no time-series survey has yet been conducted in Iran, therefore, the default data provided by WHO for the AirQ software were used. In the APHEA project, RHR amounts for $\mathrm{NO}_{2}, \mathrm{SO}_{2}$, and $\mathrm{O}_{3}$ were obtained from previous studies (Touloumi et al., 1996).

\subsection{Data collection}

In the current research, the information for air pollutants of $\mathrm{O}_{3}$, $\mathrm{NO}_{2}$, and $\mathrm{SO}_{2}$ was supplied by the Fars's Institute of Environment. Two fixed monitors of criteria air pollution in the Shiraz city (Caserone gate and Setad stations) were used which cover the data from January 2015 to January 2017. The model of the devices in both stations was Environ-Tech. The devices are checked, adjusted, and calibrated according to the program of the Iranian Department of Environment. The map of fixed-air monitoring stations in the Shiraz city is illustrated in Fig. 1.

The air pollution data were entered into Microsoft Excel format. Therefore, the information was transformed into the required format for the AirQ software. Before evaluation, data must be analyzed based on criteria listed by WHO including, the ratio of the number of valid data for the summer season to the winter data and vice versa should not be more than 2 and to achieve an hourly average of data, at least $75 \%$ of the data must be valid.

The assessment of the adverse health effects using the AirQ software is associated with the level and type of inhaled pollutants. Thus, information units were modified to the weight-volume unit $\left(\mathrm{g} / \mu^{3}\right)$ based on temperature and pressure conditions for the gaseous contaminants and then categorized at the intervals of $10 \mu \mathrm{g} / \mathrm{m}^{3}$. For all oxidative air contaminates, maximum annual, average seasonal, and 98th percentiles were calculated. The data were also represented as "daily".

\section{Result and discussion}

\subsection{The level of air pollutants in the Shiraz atmosphere}

The statistical findings of the oxidant pollutants survived in this study have been showing in Table 1. From findings, the highest annual levels for $\mathrm{O}_{3}, \mathrm{NO}_{2}$, and $\mathrm{SO}_{2}$ were obtained 187.33, 34.1, and $491.2 \mu \mathrm{g} / \mathrm{m}^{3}$ in 2016, respectively, and whereas for 2017 the maximum level for these pollutants was found to be 227.75, 92.26, and $190.21 \mu \mathrm{g} / \mathrm{m}^{3}$, respectively, in 2017. Among the pollutants mentioned above, the yearly average concentration of $\mathrm{SO}_{2}$ was 8.62 times more than the WHO guideline, during study times (World Health Organization, ?2006). A possible reason for this issue is the low quality of fuel in Iran.

Considering the results listed in Table 1, the concentrations of $\mathrm{O}_{3}$ and $\mathrm{SO}_{2}$ in summer were higher than in winter. This can be interpreted by the enhance in photochemical activity with high temperature due to the increase in the intensity of solar radiation, the intensity of dust storms, the lack of adequate rainfall, and low wind speed in this session (Asl et al., 2018). Based on the research of Fattore et al. (2011), the maximum $\mathrm{NO}_{2}$ concentration, $76 \mathrm{mg} / \mathrm{m}^{3}$ was detected in winter, while the maximum concentration of $\mathrm{O}_{3}$ $\left(174 \mathrm{mg} / \mathrm{m}^{3}\right)$ was obtained in summer. Significant negative correlations were stated between the atmospheric pollutants and atmospheric conditions (wind speed and relative humidity) (Asl et al., 2018).

From Table 1, the level of pollutants in summer has enhanced significantly compared to winter (P-value $<0.05$ ), which can be attributed to increased adverse atmospheric conditions and high traffic in Shiraz city, which this is due to the tourist arrival in the city and also sulfur content in the fuel of vehicles (Gharehchahi et al., 2013; Chu Van et al., 2018). The results of this study are consistent with other studies (Ooka et al., 2011; Kalabokas et al., 2013).

\subsection{Hospital admission due to asthmatic disease based on the AirQ software}

In this study, health outcomes resulting from short-term exposure to oxidant pollutants including $\mathrm{O}_{3}, \mathrm{NO}_{2}$, and $\mathrm{SO}_{2}$, were measured by using the AirQ model in different scenarios. Table 2 shows incidence, RHR, AE, and the number of extra cases in a year due to short-term exposure above $10 \mu \mathrm{g} / \mathrm{m}^{3}$ for $\mathrm{O}_{3}, \mathrm{NO}_{2}$, and $\mathrm{SO}_{2}$. Based on the results depicted in Table 2, the maximum attributable equivalent $(\mathrm{AE})$ for $\mathrm{HAAD}<15$ years old was related to $\mathrm{SO}_{2}$ with $14.44 \%$ and $18.18 \%$, respectively, in both 2016 and 2017.

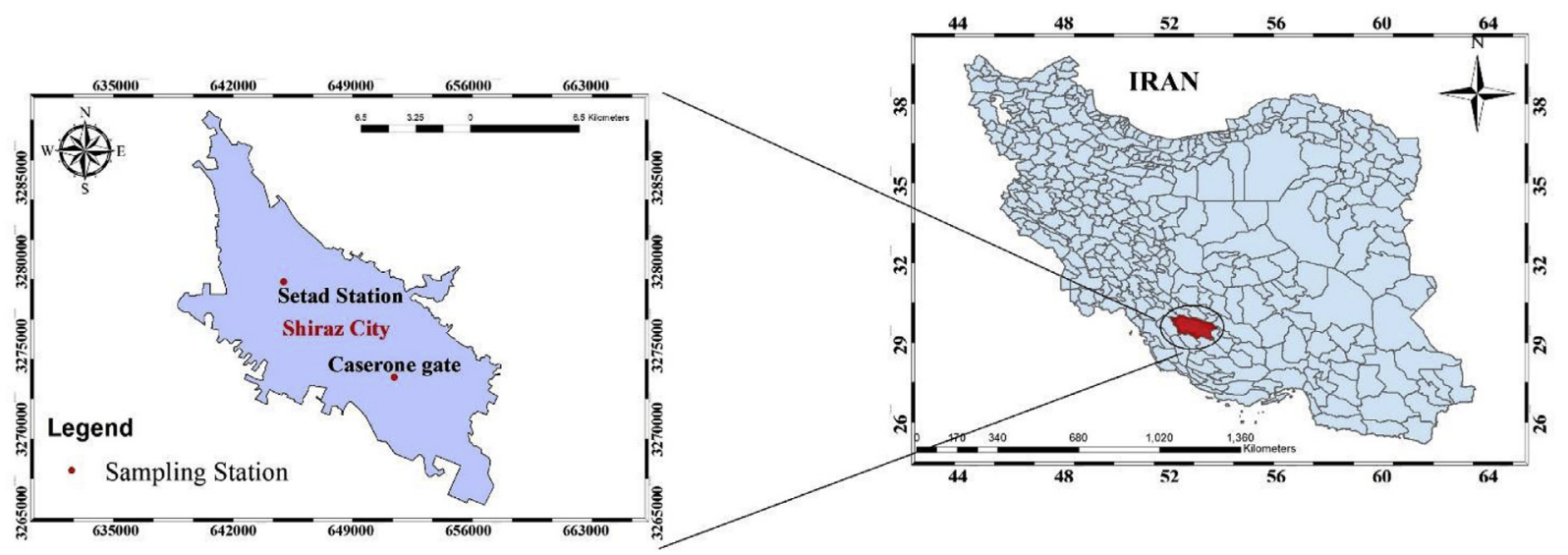

Fig. 1. The investigated area and air monitoring sites (Shiraz, Iran). 
Table 1

Summary of the concentrations of studied air pollutants $\left(\mu \mathrm{g} / \mathrm{m}^{3}\right)$ in Shiraz city during 2015-2017.

\begin{tabular}{|c|c|c|c|c|c|c|c|}
\hline \multirow[t]{2}{*}{ Parameter } & & \multicolumn{2}{|l|}{$\mathrm{O}_{3}$} & \multicolumn{2}{|l|}{$\mathrm{NO}_{2}$} & \multicolumn{2}{|l|}{$\mathrm{SO}_{2}$} \\
\hline & & $2015-2016$ & 2016-2017 & $2015-2016$ & $2016-2017$ & 2015-2016 & 2016-2017 \\
\hline \multirow[t]{4}{*}{ Average } & Annual & 46.16 & 45.31 & 14.35 & 16.45 & 120.05 & 52.58 \\
\hline & Summer & 36.48 & 43.83 & 17.95 & 5.59 & 95.85 & 70.06 \\
\hline & Winter & 72.04 & 45.81 & 10.43 & 28.18 & 149.61 & 39.58 \\
\hline & 98 percentiles annual & 155.34 & 155.93 & 31.14 & 92.12 & 437.19 & 177.19 \\
\hline \multirow[t]{3}{*}{ Maximum } & Annual & 187.33 & 227.75 & 34.1 & 92.26 & 491.23 & 190.21 \\
\hline & Summer & 108.76 & 227.75 & 34.1 & 6.58 & 491.23 & 190.21 \\
\hline & Winter & 99.07 & 15814 & 19.72 & 92.26 & 404.51 & 133.59 \\
\hline
\end{tabular}

While, the highest AE for HAAD > 15-64 years was attributed to $\mathrm{O}_{3}$ with $2.71 \%$ and $2.36 \%$, respectively, in 2016 and 2017. From Table 2, the number of extra cases for HAAD $<15$ and HAAD $>15-64$ caused by oxidant air pollutants in Shiraz was estimated to be 273 and 36 cases, respectively, in 2016, and the values for equivalent pollutants during the year 2017 were observed as 243 and 30 cases. Fig. 2 indicates the relationship between oxidant pollutant concentrations and the cumulative number of HAAD $<15$ years and HADD $>15-64$ years in central RHR from 2016 to 2017. As shown in Fig. 2, the number of excess cases for HAAD $<15$ related to $\mathrm{SO}_{2}$ is higher than those of other oxidant pollutants in both 2016 and 2017. Also, findings showed that the impact of this pollutant on the age group less than 15 years old is more severe than that of the age group of 15-64 years old. This finding may be due to the high sensitivity of children/teenagers with inflammatory markers to oxidative stress correlated to atmospheric pollution and, therefore, the asthma risk is greater for this age group (Delfino et al., 2014). These findings demonstrate the irrefutable portion of air contaminants on the overall mortality cases produced by respiratory diseases (Karimi et al., 2019; Phosri et al., 2019). On the other hand, some researchers proposed the adverse health effects of pollutants at fewer levels than the recommended values of atmospheric pollutant guidelines (like WHO or USEPA guidelines), which reveals the weakness of standards to conserve people's health.

In a systematic review performed by Clark et al. (2010), $\mathrm{NO}_{2}$ was introduced as the most important pollutant causing asthma. They also expressed that $\mathrm{SO}_{2}$ in industrial areas was related to asthma risk. Many other types of research have also shown that trafficrelated air pollution causes a probability of asthma disease (Brauer et al., 2007; Morgenstern et al., 2008; Mortimer et al., 2008; Strickland et al., 2010). The $\mathrm{NO}_{2}$ gas acts as a basic proxy for traffic- related air pollution (TRAP) and is the main part of urban air pollution, primarily caused by the combustion of fossil fuels, and yet, traffic and road pollution were correlated with up to $80 \%$ of atmospheric $\mathrm{NO}_{2}$ in cities. The involvement of exposure to $\mathrm{NO}_{2}$ in pediatric asthma is due largely to the activation of innate immune responses (Liu et al., 2020).

According to the findings of Fig. 2, the number of extra cases for HAAD >15-64 years was mainly attributed to $\mathrm{O}_{3}$ in both 2016 and 2017. The cumulative number of hospitalizations was increased in a concentration of more than $30 \mathrm{ppb} \mathrm{O}_{3}$. The sources of $\mathrm{O}_{3}$ include the VOCs and $\mathrm{CO}$ emissions from industries, high traffic districts, as well as incomplete combustion in residential areas. The photochemical reaction between nitrogen oxides, volatile organic compounds, heat, and sunlight is the predominant mechanism to produce atmospheric $\mathrm{O}_{3}$ (Goudarzi et al., 2015; Asl et al., 2018). The impact of exposure to $\mathrm{O}_{3}$ on pediatric asthma is complex, as $\mathrm{O}_{3}$ can function in two opposite ways, in that $\mathrm{O}_{3}$ has both inflammatory and antiviral effects. Ozone via the production of oxygen radicals increases oxidative stress, inflammation, and epithelial cell damage, which may cause asthma exacerbation, whereas $\mathrm{O}_{3}$ has also been observed to be protective from some respiratory viral infections, which is an initial precipitating factor for pediatric asthma (Liu et al., 2020). Based on the effect of air pollutants in warm weather on Australian children in a specific period, it has been expressed that ozone has the greatest a five-day cumulative effect and enhanced $11.7 \%$ (95\% CI 5.8-17.9\%) the HAAD risk for children per $10 \mathrm{ppb}$ increase in the ozone level (Chen et al., 2016). Gryparis et al. (2004) in the study on 23 cities/areas throughout Europe have been stated that an increase in the $\mathrm{O}_{3}$ level by $10 \mu \mathrm{g} / \mathrm{m}^{3}$ is associated with $1.13 \%$ (95\% CI, $0.62-1.48$ ) in the number of the deaths due to respiratory diseases.

Table 2

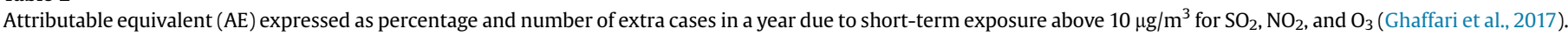

\begin{tabular}{|c|c|c|c|c|c|c|c|}
\hline \multirow[t]{2}{*}{ Health endpoint } & \multirow[t]{2}{*}{ Incidence $^{a}$} & \multirow{2}{*}{$\begin{array}{l}\operatorname{RHR}\left(95 \% \mathrm{CI}^{\mathrm{b}}\right) \text { per } 10 \mu \mathrm{g} / \\
\mathrm{m}^{3}\end{array}$} & \multirow[t]{2}{*}{ Pollutant } & \multicolumn{2}{|l|}{ Estimated $\mathrm{AE}(\%)^{\mathrm{c}}$} & \multicolumn{2}{|c|}{ Extra cases (uncertainty range) ${ }^{c}$} \\
\hline & & & & 2015-2016 & $2016-2017$ & 2015-2016 & $2016-2017$ \\
\hline \multirow[t]{3}{*}{ Hospital admissions asthma $<15$ years } & 100 & $1.0012(1-1.0074)^{\mathrm{d}}$ & $\mathrm{O}_{3}$ & $0.00(0.00-2.94)$ & $0.00(0.00-2.55)$ & $0.0(0.0-54.8)$ & $0.0(0.0-47.6)$ \\
\hline & 100 & $1.0052(1.0012-1.0098)^{\mathrm{e}}$ & $\mathrm{NO}_{2}$ & $\begin{array}{l}0.273(0.063 \\
-0.514)\end{array}$ & $\begin{array}{l}0.064(0.014 \\
-0.121)\end{array}$ & $5.1(1.2-9.6)$ & $1.2(0.3-2.3)$ \\
\hline & 100 & $1.015(1.0052-1.025)^{\mathrm{e}}$ & $\mathrm{SO}_{2}$ & $14.44(5.53-21.96)$ & $13.02(4.93-19.97)$ & $\begin{array}{l}268.8(102.9 \\
-408.6)\end{array}$ & $\begin{array}{l}242.3(91.8 \\
-371.6)\end{array}$ \\
\hline \multirow{3}{*}{$\begin{array}{l}\text { Hospital admissions asthma }>15-64 \\
\quad \text { years }\end{array}$} & 66 & $1.003(1-1.0156)$ & $\mathrm{O}_{3}$ & $2.71(0.00-10.31)$ & $2.36(0.00-9.05)$ & $33.4(0.0-126.6)$ & $29(0.0-111.1)$ \\
\hline & 66 & $1.0058(1.0006-1.011)$ & $\mathrm{NO}_{2}$ & $\begin{array}{l}0.305(0.031 \\
-0.577)\end{array}$ & $\begin{array}{l}0.071(0.007 \\
-0.135)\end{array}$ & $3.7(0.4-7.1)$ & $1(0.1-1.7)$ \\
\hline & 66 & $1(1-1.0068)$ & $\mathrm{SO}_{2}$ & $0.00(0.00-7.11)$ & $0.00(0.00-6.36)$ & $0.00(0.00-87.3)$ & $0.0(0.0-78.1)$ \\
\hline
\end{tabular}

\footnotetext{
a Crude rate per 100,000 inhabitants.

b CI: Confidence intervals.

c Obtained using the lower and upper RHR values.

d $1 \mathrm{~h}$ average.

e Daily average.
} 

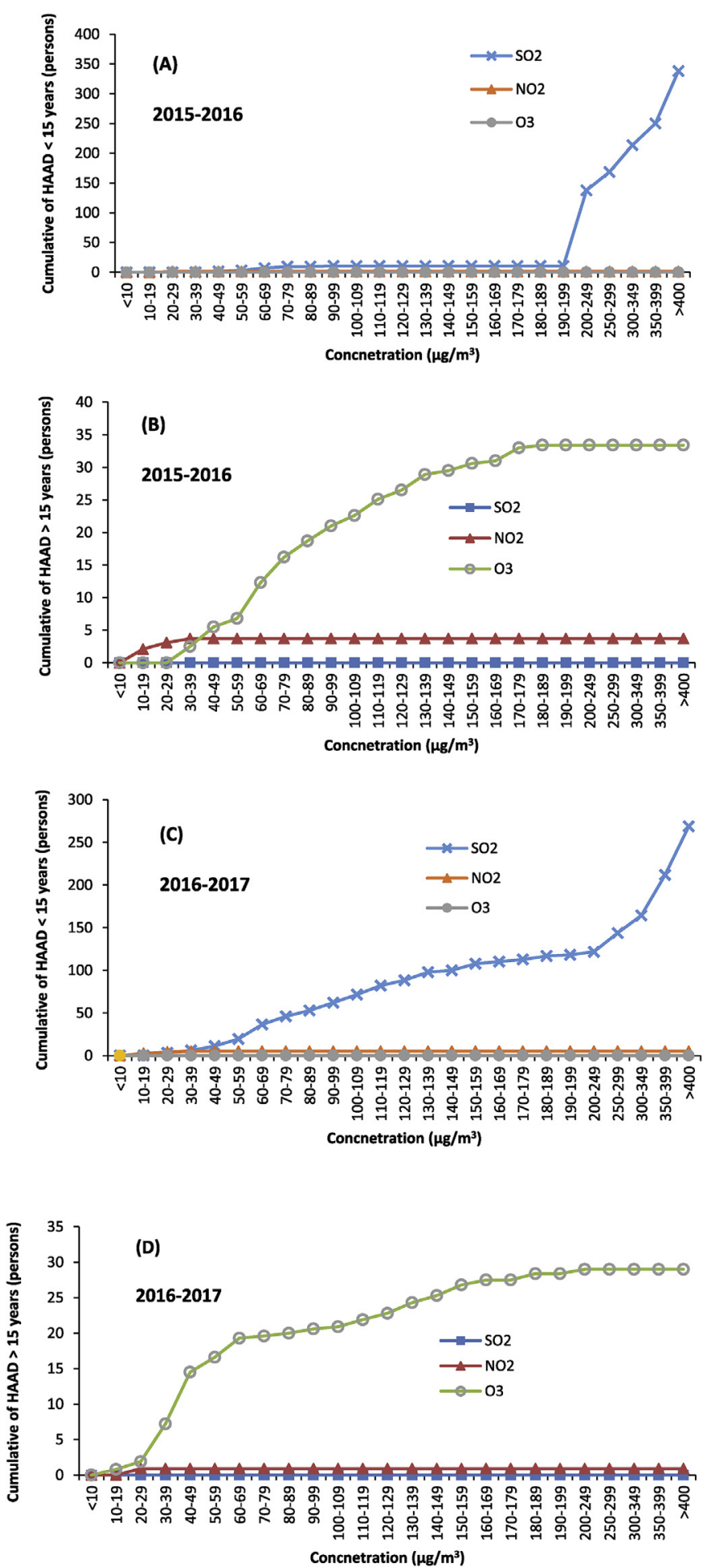

Fig. 2. Relationship between pollutants concentration and cumulative number of HAAD (A) < 15 years old during 2015-2016, (B) > 15 years old during 2015-2016, (C) < 15 years old during 2016-2017, and (D) > 15 years old during 2016-2017.

\subsection{Limitations of this research}

Although the use of AirQ software is developed and recommended by the World Health Organization, it has some shortcomings.

This software considers the effects of each pollutant separately, while the toxicity of the pollutant in the atmosphere may change under conditions of light and volatile organic matter (Naclerio et al.,
2020). Therefore, this software is unaware of the cumulative effects of atmospheric pollutants on humans. However, there are several reports that climatic conditions, global warming, and new factors could affect the health effects of pollutants in the atmosphere (D’Amato et al., 2015; Kajino et al., 2017).

The RHR factor is based on reports from American and European countries that have different demographic characteristics, and its generalization to developing countries could take the results far from reality. Therefore, the researchers of each country should obtain and apply this factor based on the field data.

A further limitation is that the approach assumes that the concentration of pollutants measured in specific sampling points is representative of the average exposure of people living in Shiraz city with an area of $\sim 240 \mathrm{~km}^{2}$. One solution is to use mobile stations.

The software assumes that all people are equally exposed to pollutants and exposed to them all the time, although we know this is not the case.

Despite the shortcomings, the World Health Organization (WHO) has proposed to use this tool for calculating the health effect of criteria air pollutants and various well-known editors around the world have accepted the application of AirQ software (Asl et al., 2018; Bonyadi et al., 2020; Luo et al., 2020; Rovira et al., 2020).

\section{Conclusions}

The overall goal of this study was to calculate the relationship between hospital admissions due to asthma and airborne pollutants $\left(\mathrm{NO}_{2}, \mathrm{SO}_{2}\right.$, and $\left.\mathrm{O}_{3}\right)$ during the years 2015-2017. Based on findings, Shiraz city had the maximum concentration of pollutants in the years 2016 and 2017 was corresponded to $\mathrm{SO}_{2}$ and $\mathrm{O}_{3}$, respectively. The yearly average concentration of $\mathrm{SO}_{2}$ was 8.62 times more than the WHO guideline, during study times. Accordingly, this pollutant had the maximum adverse effect on Shiraz citizenships' health. In the study area for both 2016 and 2017, the highest number of extra cases were linked to $\mathrm{SO}_{2}$ and $\mathrm{O}_{3}$ with the most effect on HAAD $<15$ and HAAD $>15$ years, respectively. This research suggests to local and regional policymakers that management programs like public transportation development and fossil fuel substitution need to be implemented to reduce the air pollutants concentration as much as possible. Finally, although some studies have used this model to estimate health impacts due to exposure to air pollution, we also suggest this model for the evaluation of HAAD.

\section{Authorship Contribution Statement}

Ziaeddin Bonyadi: Software, Writing - original draft. Hossein Arfaeinia: Methodology, Conceptualization. Moradali Fouladvand: Conceptualization and review. Sima Farjadfard: Methodology. Mohsen Omidvar: Methodology, Validation. Bahman Ramavandi: Supervision, review\& editting.

\section{Declaration of competing interest}

The authors declare that they have no known competing financial interests or personal relationships that could have appeared to influence the work reported in this paper.

\section{Acknowledgments}

The authors of this paper would like to acknowledge the Fars's Institute of Environment and Weather Department of Fars Province for providing the raw data. 


\section{References}

Asl, F.B., Leili, M., Vaziri, Y., Arian, S.S., Cristaldi, A., Conti, G.O., Ferrante, M., 2018. Health impacts quantification of ambient air pollutants using AirQ model approach in Hamadan, Iran. Environ. Res. 161, 114-121.

Bonyadi, Z., Arfaeinia, H., Ramavandi, B., Omidvar, M., Asadi, R., 2020. Quantification of mortality and morbidity attributed to the ambient air criteria pollutants in Shiraz city, Iran. Chemosphere 257, 127233.

Brauer, M., Hoek, G., Smit, H., De Jongste, J., Gerritsen, J., Postma, D.S., Kerkhof, M., Brunekreef, B., 2007. Air pollution and development of asthma, allergy and infections in a birth cohort. Eur. Respir. J. 29, 879-888.

Chen, K., Glonek, G., Hansen, A., Williams, S., Tuke, J., Salter, A., Bi, P., 2016. The effects of air pollution on asthma hospital admissions in Adelaide, South Australia, 2003-2013: time-series and case-crossover analyses. Clin. Exp. Allergy 46, 1416-1430.

Chu Van, T., Ristovski, Z., Surawski, N., Bodisco, T.A., Rahman, S.M.A., Alroe, J., Miljevic, B., Hossain, F.M., Suara, K., Rainey, T., Brown, R.J., 2018. Effect of sulphur and vanadium spiked fuels on particle characteristics and engine performance of auxiliary diesel engines. Environ. Pol. 243, 1943-1951.

Clark, N.A., Demers, P.A., Karr, C.J., Koehoorn, M., Lencar, C., Tamburic, L., Brauer, M., 2010. Effect of early life exposure to air pollution on development of childhood asthma. Environ. Health Perspect. 118, 284-290.

Conti, G.O., Heibati, B., Kloog, I., Fiore, M., Ferrante, M., 2017. A review of AirQ Models and their applications for forecasting the air pollution health outcomes. Environ. Sci. Pollut. Res. 24, 6426-6445.

D’Amato, G., Holgate, S.T., Pawankar, R., Ledford, D.K., Cecchi, L., Al-Ahmad, M., AlEnezi, F., Al-Muhsen, S., Ansotegui, I., Baena-Cagnani, C.E., Baker, D.J., Bayram, H., Bergmann, K.C., Boulet, L.-P., Buters, J.T.M., D’Amato, M., Dorsano, S., Douwes, J., Finlay, S.E., Garrasi, D., Gómez, M., Haahtela, T., Halwani, R. Hassani, Y., Mahboub, B., Marks, G., Michelozzi, P., Montagni, M., Nunes, C., Oh, J.J.-W., Popov, T.A., Portnoy, J., Ridolo, E., Rosário, N., Rottem, M., SánchezBorges, M., Sibanda, E. Sienra-Monge, J.., Vitale, C. Annesi-Maesano, I., 2015. Meteorological conditions, climate change, new emerging factors, and asthma and related allergic disorders. A statement of the World Allergy Organization. World Allergy Organ. J. 8, 25.

Delfino, R.J., Wu, J., Tjoa, T., Gullesserian, S.K., Nickerson, B., Gillen, D.L., 2014. Asthma morbidity and ambient air pollution: effect modification by residential traffic-related air pollution. Epidemiology 48-57.

Fattore, E., Paiano, V., Borgini, A., Tittarelli, A., Bertoldi, M., Crosignani, P., Fanelli, R., 2011. Human health risk in relation to air quality in two municipalities in an industrialized area of Northern Italy. Environ. Res. 111, 1321-1327.

Ghaffari, H.R., Aval, H.E., Alahabadi, A., Mokammel, A., Khamirchi, R. Yousefzadeh, S., Ahmadi, E., Rahmani-Sani, A., Estaji, M., Ghanbarnejad, A., 2017. Asthma disease as cause of admission to hospitals due to exposure to ambient oxidants in Mashhad, Iran. Environ. Sci. Pollut. Res. 24, 27402-27408.

Gharehchahi, E., Mahvi, A.H., Amini, H., Nabizadeh, R., Akhlaghi, A.A. Shamsipour, M., Yunesian, M., 2013. Health impact assessment of air pollution in Shiraz, Iran: a two-part study. J. Environ. Health Sci. Eng. 11, 11.

Goudarzi, G., Geravandi, S., Foruozandeh, H., Babaei, A.A., Alavi, N., Niri, M.V. Khodayar, M.J., Salmanzadeh, S., Mohammadi, M.J., 2015. Cardiovascular and respiratory mortality attributed to ground-level ozone in Ahvaz, Iran. Environ. Monit. Assess. 187, 487.

Gryparis, A., Forsberg, B., Katsouyanni, K., Analitis, A., Touloumi, G., Schwartz, J., Samoli, E., Medina, S., Anderson, H.R., Niciu, E.M., 2004. Acute effects of ozone on mortality from the "air pollution and health: a European approach" project. Am. J. Respir. Crit. Care Med. 170, 1080-1087.

Hauptman, M., Gaffin, J.M., Petty, C.R., Sheehan, W.J., Lai, P.S., Coull, B., Gold, D.R., Phipatanakul, W., 2020. Proximity to major roadways and asthma symptoms in the school inner-city asthma study. J. Allergy Clin. Immunol. 145, 119-126 e114.

Kajino, M., Ueda, H., Han, Z., Kudo, R., Inomata, Y., Kaku, H., 2017. Synergy between air pollution and urban meteorological changes through aerosol-radiationdiffusion feedback-A case study of Beijing in January 2013. Atmos. Environ. 171, 98-110.

Kalabokas, P., Cammas, J.-P., Thouret, V., Volz-Thomas, A., Boulanger, D., Repapis, C., 2013. Examination of the atmospheric conditions associated with high and low summer ozone levels in the lower troposphere over the Eastern Mediterranean. Atmos. Chem. Phys. 13.

Karimi, B., shokrinezhad, B., Samadi, S., 2019. Mortality and hospitalizations due to cardiovascular and respiratory diseases associated with air pollution in Iran: a systematic review and meta-analysis. Atmos. Environ. 198, 438-447.

Khaniabadi, Y.O., Fanelli, R., De Marco, A., Daryanoosh, S.M., Kloog, I., Hopke, P.K., Conti, G.O., Ferrante, M., Mohammadi, M.J., Babaei, A.A., 2017. Hospital admissions in Iran for cardiovascular and respiratory diseases attributed to the Middle Eastern Dust storms. Environ. Sci. poll. Res. 24, 16860-16868.

Liu, L., Liu, C., Chen, R., Zhou, Y., Meng, X., Hong, J., Cao, L., Lu, Y., Dong, X., Xia, M.,
2020. Associations of short-term exposure to air pollution and emergency department visits for pediatric asthma in Shanghai, China. Chemosphere 127856.

Luo, H., Guan, Q., Lin, J., Wang, Q., Yang, L., Tan, Z., Wang, N., 2020. Air pollution characteristics and human health risks in key cities of northwest China. J. Environ. Manag. 269, 110791.

Miri, M., Derakhshan, Z., Allahabadi, A., Ahmadi, E., Conti, G.O., Ferrante, M. Aval, H.E., 2016. Mortality and morbidity due to exposure to outdoor air pollution in Mashhad metropolis, Iran. The AirQ model approach. Environ. Res. $151,451-457$.

Mokhtari, M., Miri, M., Mohammadi, A., Khorsandi, H., Hajizadeh, Y., Abdolahnejad, A., 2015. Assessment of air quality index and health impact of $\mathrm{PM}_{10}, \mathrm{PM}_{2.5}$ and $\mathrm{SO}_{2}$ in Yazd, Iran. J. Maz. Univ. Med. Sci. 25, 14-23.

Morgenstern, V., Zutavern, A., Cyrys, J., Brockow, I., Koletzko, S., Kramer, U. Behrendt, H., Herbarth, O., von Berg, A., Bauer, C.P., 2008. Atopic diseases, allergic sensitization, and exposure to traffic-related air pollution in children Am. J. Respir. Crit. Care Med. 177, 1331-1337.

Mortimer, K., Neugebauer, R., Lurmann, F., Alcorn, S., Balmes, J., Tager, I., 2008. Air pollution and pulmonary function in asthmatic children: effects of prenatal and lifetime exposures. Epidemiology 550-557.

Murray, C.S., Poletti, G., Kebadze, T., Morris, J., Woodcock, A., Johnston, S. Custovic, A., 2006. Study of modifiable risk factors for asthma exacerbations: virus infection and allergen exposure increase the risk of asthma hospital admissions in children. Thorax 61, 376-382.

Naclerio, R., Ansotegui, I.J., Bousquet, J., Canonica, G.W., D’Amato, G., Rosario, N. Pawankar, R., Peden, D., Bergmann, K.-C., Bielory, L., Caraballo, L., Cecchi, L., Cepeda, S.A.M., Chong Neto, H.J., Galán, C., Gonzalez Diaz, S.N., Idriss, S., Popov, T., Ramon, G.D., Ridolo, E., Rottem, M., Songnuan, W., Rouadi, P., 2020 International expert consensus on the management of allergic rhinitis (AR) aggravated by air pollutants: impact of air pollution on patients with AR: current knowledge and future strategies. World Allergy Organ. J. 13, 100106.

Nikoonahad, A., Naserifar, R., Alipour, V., Poursafar, A., Miri, M., Ghafari, H.R. Abdolahnejad, A., Nemati, S., Mohammadi, A., 2017. Assessment of hospitalization and mortality from exposure to $\mathrm{PM}_{10}$ using AirQ modeling in Ilam, Iran. Environ. Sci. Pollut. Res. 24, 21791-21796.

Ooka, R., Khiem, M., Hayami, H., Yoshikado, H., Huang, H., Kawamoto, Y., 2011. Influence of meteorological conditions on summer ozone levels in the central Kanto area of Japan. Procedia Environ. Sci. 4, 138-150.

Phosri, A., Ueda, K., Phung, V.L.H., Tawatsupa, B., Honda, A., Takano, H., 2019. Effects of ambient air pollution on daily hospital admissions for respiratory and cardiovascular diseases in Bangkok, Thailand. Sci. Total Environ. 651, 1144-1153.

Pierangeli, I., Nieuwenhuijsen, M., Cirach, M., Rojas-Rueda, D., 2020. Health equity and burden of childhood asthma-related to air pollution in Barcelona. Environ. Res., 109067

Poole, J.A., Barnes, C.S., Demain, J.G., Bernstein, J.A., Padukudru, M.A., Sheehan, W.J. Fogelbach, G.G., Wedner, J., Codina, R., Levetin, E., Cohn, J.R., Kagen, S., Portnoy, J.M., Nel, A.E., 2019. Impact of weather and climate change with indoor and outdoor air quality in asthma: a work group report of the aaaai environmental exposure and respiratory health committee. J. Allergy Clin. Immunol. $143,1702-1710$.

Riedl, M., Diaz-Sanchez, D., 2005. Biology of diesel exhaust effects on respiratory function. J. Allergy Clin. Immunol. 115, 221-228.

Rovira, J., Domingo, J.L., Schuhmacher, M., 2020. Air quality, health impacts and burden of disease due to air pollution $\left(\mathrm{PM}_{10}, \mathrm{PM}_{2.5}, \mathrm{NO}_{2}\right.$ and $\left.\mathrm{O}_{3}\right)$ : application of AirQ + model to the Camp de Tarragona County (Catalonia, Spain). Sci. Total Environ. 703, 135538.

Seifi, M., Niazi, S., Johnson, G., Nodehi, V., Yunesian, M., 2019. Exposure to ambient air pollution and risk of childhood cancers: a population-based study in Tehran, Iran. Sci. Total Environ. 646, 105-110.

Strickland, M.J., Darrow, L.A., Klein, M., Flanders, W.D., Sarnat, J.A., Waller, L.A., Sarnat, S.E., Mulholland, J.A., Tolbert, P.E., 2010. Short-term associations between ambient air pollutants and pediatric asthma emergency department visits. Am. J. Respir. Crit. Care Med. 182, 307-316.

To, T., Shen, S., Atenafu, E.G., Guan, J., McLimont, S., Stocks, B., Licskai, C., 2013. The air quality health index and asthma morbidity: a population-based study. Environ. Health Perspect. 121, 46-52.

Touloumi, G., Samoli, E., Katsouyanni, K., 1996. Daily mortality and" winter type" air pollution in Athens, Greece-a time series analysis within the APHEA project. J. Epidemiol. Community Health 50, s47-s51.

Trasande, L., Thurston, G.D., 2005. The role of air pollution in asthma and other pediatric morbidities. J. Allergy Clin. Immunol. 115, 689-699.

World Health Organization. Occupational and Environmental Health Team, 2006 WHO Air Quality Guidelines for Particulate Matter, Ozone, Nitrogen Dioxide and Sulfur Dioxide: Global Update 2005: Summary of Risk Assessment. World Health Organization. 